\title{
Transient hypothyroidism after withdrawal of thyroxin therapy
}

\author{
L. A. Distiller \\ B.Sc., M.B., F.C.P.
}

\author{
B. I. JOFFE \\ M.B., M.R.C.P.
}

\section{Endocrine Unit and Department of Medicine, Johannesburg Hospital and University of the Witwatersrand, Johannesburg, South Africa}

\section{Summary}

Continued administration of large doses of thyroid may not produce hyperthyroidism in euthyroid individuals. Cessation of prolonged high-dosage thyroid replacement can cause transient clinical and biochemical hypothyroidism owing to pituitary suppression. A case is recorded in which both these phenomena are well demonstrated. This case highlights these basic endocrinological principles.

\section{Introduction}

Transient hypothyroidism is well documented after subacute thyroiditis (Greene, 1971) and occasionally develops after radioactive iodine therapy (Sagel et al., 1972). Less well described is its occurrence after prolonged thyroxin therapy in a euthyroid individual. The following report deals with such a case.

\section{Case report}

A 29-year-old female presented at the Endocrine Clinic, Johannesburg Hospital, in February 1973. Her history dated back to 1964 when she gave birth to a healthy full-term infant. The delivery was followed by a large post-partum haemorrhage requiring blood transfusion. However, the patient was able to breast feed for 6 weeks. In 1965 she had a second infant which she also breast fed for 6 weeks. Following this she developed amenorrhoea. During 1969 a physician recorded a pulse rate of 60 'min, 'slow' ankle jerks and a BMR of $-15 \%$. Her PBI was $6.9 \mu \mathrm{g} / 100 \mathrm{ml}$ and, despite this, she was started on L-thyroxin $0.1 \mathrm{mg}$ daily. Her menses never returned but she felt better on the thyroxin. Over the following 4 years the dose was gradually increased to $0.8 \mathrm{mg}$ daily. Despite this massive dosage the patient felt well; repeated clinical examinations and biochemical testing indicated that she was apparently completely euthyroid (Fig. 1). During this time she had a third normal infant despite continuing amenorrhoea. She was ultimately sent to the Endocrine Clinic for a more detailed assessment of hero endocrine status. At her first visit (February 1973) she appeared a healthy young female and was totally asymptomatic on $\mathbf{0 . 8} \mathrm{mg}$ L-thyroxin daily. Her pulse was $80 / \mathrm{min}$ with normal ankle reflexes, and nothing abnormal on systemic examination. Pending further investigations thyroxin therapy was abruptly withdrawn. She was again seen in March 1973. At this visit the patient complained of lethargy and depression. She had gained $3.6 \mathrm{~kg}$ in weight and had deve-

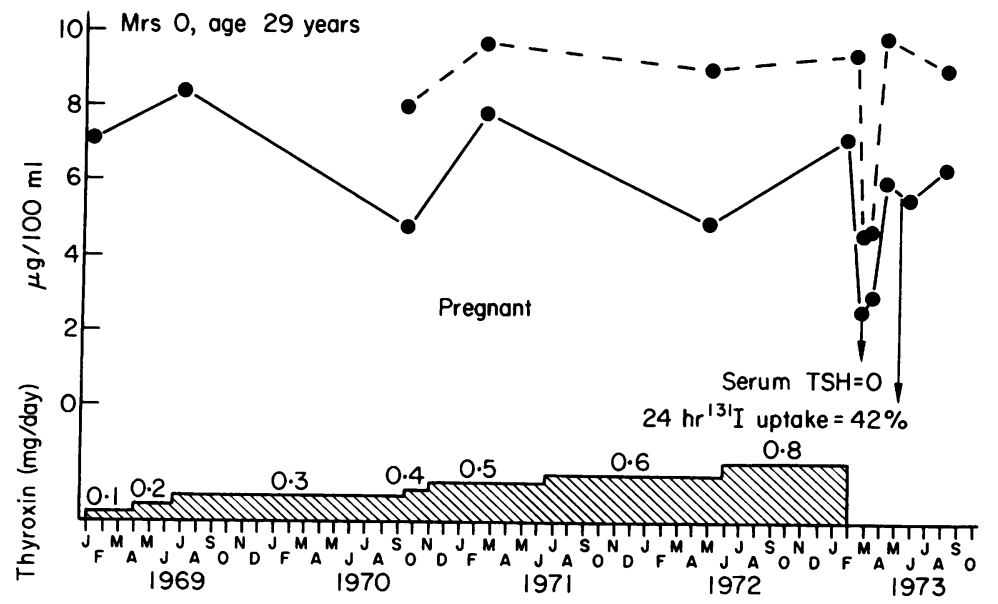

FIG. 1. This figure demonstrates the biochemical events and therapy over the period of study. PB1, _ 
loped a loss of appetite, constipation and a dry skin. On examination she had many features consistent with hypothyroidism, including a pulse rate of $54 / \mathrm{min}$. The electrocardiograph revealed a sinus bradycardia with low voltage complexes and flattened $T$ waves. Her PBI at that time was $2 \cdot 8$ $\mu \mathrm{g} / 100 \mathrm{ml}$ with a serum thyroxin of $4.5 \mu \mathrm{g} / 100 \mathrm{ml}$ (normal value $8-12 \mu \mathrm{g} / 100 \mathrm{ml}$ ). A random serum sample revealed undetectable levels of TSH by radioimmunoassay (Odell, Wilber and Paul, 1965).

The diagnosis of 'pituitary myxoedema' seemed likely but while laboratory results were awaited, the patient's clinical state improved spontaneously. By May she was clinically and biochemically euthyroid (Fig. 1). A $24 \mathrm{hr}^{131} \mathrm{I}$ uptake performed at this time was $41 \%$ confirming that the euthyroid state was not due to the patient restarting her thyroxin therapy. Her amenorrhoea persisted and on further investigation was shown to be of isolated hypothalamic origin, probably unrelated to her thyroid status.

\section{Comment}

It has been documented by Johnston, Squires and Farquharson (1951) that continued administration of large doses of thyroid commonly fails to have a sustained effect in euthyroid patients. In their series of five cases, an initial rise in BMR and PBI occurred but these fell to normal or near-normal levels after 4-6 months of continuous therapy. A decline in PBI to sub-normal levels was demonstrated when the therapy was stopped. This fall took 1 to 3 weeks and was often associated with clinical features of myxoedema, but the PBI returned to normal in 2-3 months.
This phenomenon is well demonstrated in the $\frac{3}{\infty}$ present case report. The transient hypothyroid state $\stackrel{\varrho}{\complement}$

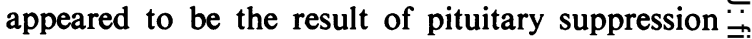
caused by exogenous thyroxin administration. Confirmatory evidence was the associated undetectable TSH level. However, as in the recorded cases above, 음 the pituitary suppression was transient, and thyroid function returned to normal within a few months. This may be compared to the well-known effect of long-term corticosteroid administration in causing pituitary suppression of adrenocorticotrophin pro- . duction. However, in the latter situation, recovery of the pituitary gland may take much longer (Cope, 1965).

Many euthyroid patients receive thyroxin therapy 3 for a variety of reasons. When the medication is $\vec{c}$ withdrawn one should be aware of the possibility of is a transient hypothyroid period. A patient should $\stackrel{0}{\bullet}$ not be labelled hypothyroid on the strength of clinical 8 or biochemical findings during the first few months after cessation of thyroid administration.

\section{References}

Cope, C.L. (1965) In: Adrenal Steroids and Disease, p. 324. Pitman, London.

Greene, J.N. (1971) Subacute thyroiditis. American Journat of Medicine, 51, 97.

Johnston, M.W., Squires, A.H. \& Farquharson, R.F (1951) The effect of prolonged administration of thyroid̄. Annals of Internal Medicine, 35, 1008.

Odell, W.D., Wilber, J.F. \& Paul, W.E. (1965) Radioimmunoassay of thyrotropin in human serum. Journal of Clinical Endocrinology and Metabolism, 25, 1179.

Sagel, J., Epstein, S., Kalk, J. \& Van Mieghem, W. (1972) Radioactive iodine ( $\left.{ }^{131} I\right)$ therapy for thyrotoxicosis at Groote Schuur Hospital over a 6-year period. Postgraduate Medical Journal, 48, 1179. 